\title{
Ankilozan spondilitli hastalarda güncel tedavi yaklaşımları
}

\section{Current treatment approaches in patients with ankylosing spondylitis}

\section{Bilal Elbey}

\section{ÖZET}

Ankilozan spondilit (AS) başlıca sakroiliak eklemler ve omurgayı etkileyen kronik, inflamatuar bir romatizmal hastalık olarak, daha çok erkeklerde sıklıkla 2. ve 3. On yılda ortaya çıkan bir hastalıktır. AS'li hastalarda tedavinin temelini ağrı ve inflamasyonu azaltan nonsteroid anti-inflamatuar ilaçlar (NSAii) almaktadır. Modifiye edici antiromatizmal (DMARD) ilaçlar, AS hastalığın tedavisinde etkinliği kanıtlanamamıştır. DMARD'ların kullanımı semptomların iyileştirilmesinde yeterli bulunmamıştır. Son zamanlarda anti tümör nekrozis faktör (TNF) blokerleri olan Golimumab, Etanersept, Adalimumab, İnfliksimab gibi ajanlar AS tedavisinde umut verici sonuçlar vermektedir. TNF blokerleri AS hastalarının fiziksel işlevlerinde, yaşam kalitesinde ve semptomlarında iyileşme sağlamaktadır. Bu yazı AS'li hastaların güncel farmakolojik tedavisi üzerine odaklanmıştır.

Anahtar kelimeler: Ankilozan spondilit, tedavi, tümör nekrozis faktör alfa inhibitörü, hastalık modifiye edici ilaçlar

\section{GíRIŞ}

Ankilozan spondilit etyolojisi net olarak bilinmeyen, genellikle erken evrede sakroiliak eklemlerde inflamasyona yol açan ve hastalık ilerledikçe aksiyel omurgayı da etkileyebilen kronik inflamatuar bir hastalıtır [1]. Yapısal ve fonksiyonel yetersizlikle birlikte inflamatuar bel ağrısına sebep olan, yaşam kalitesinde azalmaya yol açabilen bir hastalıktır. Ankilozan spondilitin tedavisi farmakolojik ve non farmakolojik tedavi yaklaşımlarını içermelidir [2].

Ankilozan spondilit değişik hastalık belirtileri olan ve uzman bir hekimin koordine ettiği multidisipliner tedaviye gerek duyulan bir hastalıktır [3].

\begin{abstract}
Ankylosing spondylitis (AS) is a chronic, inflammatory, rheumatic disease that mainly affects sacroiliac joints and spine. AS predominantly occurs more often in males and typically begins in the second or third decade. The mainstay of therapy in AS are nonsteroidal anti-inflammatory drugs, which reduce inflammation and pain. Disease modifying antirheumatic drugs (DMARD) did not have enough evidence to prove their effect in AS treatment. The use of DMARD may not sufficient to improve the treatment and symptoms. Currently, TNF-blockers such as, Golimumab Etanersept Adalimumab İnfliksimab have promising results in the treatment of AS. TNF-blockers improve the clinical signs and symptoms, and improve the patients' physical function and quality of life. This manuscript is focused that Current pharmacological treatments in patients with ankylosing spondylitis.
\end{abstract}

Key words: Ankylosing spondylitis, treatment, tumour necrosis factor alpha inhibitor, disease modifying antirheumatic drugs

Tedavideki esas amaç semptom ve inflamasyonu kontrol altında tutarak, ilerleyen yapisal hasarı engellemek ve sağlıkla ilişkili hayat kalitesini uzun dönemde en üst seviyede tutmaktır [4].

\section{FARMAKOLOJIKK TEDAVILER}

\section{A. Non-steroid Anti-İnflamatuar İlaçlar}

Ağrısı ve sabah tutukluğu olan AS'li hastalarda ilk sırada kullanılacak ilaçlardır. Ağrı giderme, antiinflamatuar etkileriyle beraber yan etkileri de görülmektedir. Yan etkiler genellikle gastrointestinal sistemde rahatsızlık, gastrit, ülser; hepatik ve renal

Dicle Üniversitesi Tıp Fakültesi İmmunoloj Anabilim Dall, Diyarbakır, Türkiye

Yazışma Adresi /Correspondence: Bilal Elbey,

Dicle Üniversitesi Tıp Fakültesi Immünoloji Anabilim Dalı, Diyarbakır, Türkiye Email: drbilalelbey@gmail.com

Geliş Tarihi / Received: 12.01.2015, Kabul Tarihi / Accepted: 11.02.2015

Copyright @ Dicle Tıp Dergisi 2015, Her hakkı saklıdır / All rights reserved 
fonksiyon bozukluğu ve nadiren kemik iliği süpresyonu şeklindedir [4].

\section{B. Analjezikler}

Narkotik ve narkotik olmayan olarak ikiye ayrilırlar. Narkotik olanların etki mekanizması geniş iken narkotik olmayanlar basit analjeziklerdir. Narkotik olmayanlar paraaminofenol türevleri, antranilik asit ve salisilik asit türevleridir. Daha önceden uygulanan tedavilere yanit alınamadiysa, tedaviler tolere edilemediyse veya kontrendikasyon varsa parasetamol veya opioid grubu ilaçlar ağrı kontrolü için kullanılabilir [4]. Asetaminofen aspirinle benzer analjezik etkinliğe sahip olmasının yanında gastrik toksisiteye ve renal toksisiteye neden olmamaktadır (çok uzun kullanımlar hariç) [5-6]. Mefenamik asit aspirine eşdeğer etki etki göstermesine rağmen daha fazla yan etkisi vardır. Salisilik asit türevleri toksisitesi düşük, antipiretik etkileri mevcut ve COX1 ve COX2'yi daha güçlü inhibe ederler. Doz olarak günde 3-6 gr veya 20-30 mg/dl alınmalıdır [7].

\section{Kortikosteroidler}

Romatoid artrit (RA), sistemik lupus eritematozus gibi diğer inflamatuar romatizmal hastalıkların aksine, sistemik steroid tedavisi AS'li hastaların tedavisinde önemli rol oynamaz [8]. Gebelik ve inflamatuar bağırsak hastalığı gibi NSAİI kullanımının kontrendike olduğu durumlarda sistemik steroid kullanılabileceğini öneren uzman görüşü vardır [9]. Periferal eklemler ve entezitler için lokal steroid enjeksiyonları yapılabilir. Mevcut tedavilere yanit vermeyen veya tedavilerin kontrendike olduğu aktif sakroileitli hastalarda sakroiliak ekleme steroid enjeksiyonun etkin olduğu gösterilmiştir [10].

\section{Hastalık Modifiye Edici anti-Romatizmal İlaçlar (Disease Modifying Anti- Rheumatic Drugs, DMARD)}

AS'li hastaların aksiyel belirtilerinde etkin değilken periferik belirtilerde yararlı olabilirler [11]. Sülfasalazin; sulfonamid türevi olan sülfapiridin ve antiinflamatuar olan salisilat türevi 5-aminosalisilatın bir azo bağıyla kimyasal bağlanması sonucu oluşan sentetik bir ilaçtır. Özellikle AS'de HLA-B27 pozitif artropatilerde etkinliği kabul edilmiştir [12]. Erken hastalık evresinde olan, eritrosit çökme hızı yüksek, periferik artriti olan hastalarda ve anterior üveiti önlemek için kullanılabilirler [4].

\section{E. Biyolojik Tedaviler}

Aksiyel tutulumu olan AS'li hastalar, ilk basamak tedavi olarak kullanılan NSAIİ ve periferal tutulumu olan hastalar ek olarak SLZ gibi bir DMARD kullanılmasına rağmen halen aktif ise tedavide ikinci basamak ilaç olarak anti-TNF- $\alpha$ ilaçlar kullanılmaktadır [13].

Anti-TNF- $\alpha$ tedavisinin immünmodülatör mekanizmalarının daha iyi kavranması infliksimab ile tedavi edilen spondiloartropatili hastalardan alınan sinovyal biyopsi analiziyle olmuştur. Anti-TNF- $\alpha$ tedavilerinin günlük pratikte kullanılmasıyla birlikte AS tedavisinde yeni bir dönem başlamıştır. Türkiye'de şu anda infliksimab, etanersept, adalimumab ve golimumab AS'li hastaların tedavisinde onaylanmıştır. Anti-TNF- $\alpha$ tedaviler hastaların büyük bir oranında semptom ve bulguların düzelmesine yardımcı olmaktadır. Sakroiliak ve omurga magnetik rezonans (MR) Görüntülerinde gösterilen akut inflamasyonu azaltmaktadırlar. Genel olarak anti-TNF- $\alpha$ hastalık süresinin kısa olması $\mathrm{C}$ reaktif proteinin artmış olması ve hastalık yaşının genç olması daha iyi yanıt almamıza yardımcı olmaktadır [14]. AS'de TNF bloke edici ajanlar dişında diğer biyolojik ajanların kullanımını önerecek kanıt mevcut değildir [15].

Anti -TNF- $\alpha$ tedavilerin enfeksiyon, malignite, hematolojik bozukluklar, demiyelinize edici bozukluklar, otoantikor / otoimmünite gelişimi, konjestif kalp yetmezliği ve aşırı duyarlık reaksiyonları gibi birçok yan etkisi bildirilmiştir Ayrıca hamile ya da emziren hastalarda, aktif enfeksiyonu olan hastalarda, lupus ve multipl skleroz hastalarında ve malignite durumlarında kontrendikedir [2].

ASAS (2010) k1lavuzuna göre anti-TNF tedavisine geçmek için gerekli olan kriterler şunlardır

a. Dört haftadan uzun süren, "Bath Ankylosing Spondylitis Activity Index (BASDAI)" skoru $\geq 4$ ve uzman görüşü ile desteklenen aktif hastalık olmalidir.

b. Hastalar en az iki DMARD'1 en az dört hafta boyunca kullanmış olmalıdır.

c. Periferik artriti olan hastalar en az bir lokal kortikosteroid enjeksiyonuna yanıt vermemiş olmalidir.

d. Periferik artrit için hastalar en az 12 hafta sülfasalazin almış olmalıdır. 
e. Enteziti olan hastalar lokal tedaviye yanıt vermemiş olmalıdır.

f. Saf aksiyel tutulumu olan hastaların anti-TNF öncesi DMARD ile tedavi edilmesi zorunlu değildir. AS tedavisinde kullanılan dört anti-TNF blokeri mevcuttur. Tüm anti-TNF ajanlarının BASDAI \%50 düzelme kriteri ve ASAS 40 düzelme kriterleri üzerindeki etkilerinin benzer olduğu birçok çalışmada kanıtlanmıştır [16-20].

\section{Golimumab (GLM)}

Golimumab, TNF- $\alpha$ aktivitesini nötralize eden insan spesifik IgG1 kappa monoklonal antikordur. Anti-TNF tedavi öncesi hastalar, tedaviye uygunlukları açısından değerlendirilmelidir. Her ay aynı tarihte olmak üzere ayda bir defa, $50 \mathrm{mg}$, subkutan (iv formu da mevcuttur) enjekte edilir. 3-4 dozdan sonra fayda elde edilemeyen hastalarda tedavi gözden geçirilmelidir [21-22].

\section{Etanersept}

Rekombinant çözünür, IgG' nin Fc parçasına bağl1 iki adet p75 TNF reseptörünü içeren bir insan füzyon proteinidir [23]. Makrofaj ve T hücrelerde öncül protein olarak üretilir. Bu yapı TNF- $\alpha$ çevirici enzim tarafından parçalanarak çözülür ve TNF- $\alpha$ meydana çıkar [24]. Bu molekül daha sonra aktif formuna dönüşür [25]. AS de etanerseptin etkinliğini gösteren çalışmalar 2002 de yapılmıştır [26]. Bir çalışma sonunda plasebo grubuna göre $50 \mathrm{mg} /$ hafta etanersept alan kişilerde anlamlı yanıt alınmıştır. Ayrıca C reaktif protein (CRP), sedimentasyon h1zında iyileşmeler görülmüştür [27]. Yapılan başka bir plasebo karşıllaştırmalı çalışmada 27 haftalık takipte $\% 75$ relaps rapor edilmiştir [28]. Yarılanma ömrü 3-5 gün olduğundan yetişkinlerde $50 \mathrm{mg}$ subkutan olarak uygulanmaktadır [23].

\section{Adalimumab}

Rekombinant insan IgG1 olup her iki yüzeyel hücre reseptörlerini bask1layan (P55 ve P75) monoklonal anti-TNF antikorudur. Adalimumab akut faz belirteçlerinden CRP sedim ve serum sitokin düzeylerini hızla düşürür. Biyoyarlılık oranı \% 64'tür [28]. Adalimumab İki haftada bir subkutan 40 mg metotreksat veya diğer düzenleyici ilaçlarla uygulanabilir [30-31].

\section{İnfliksimab}

Monoklonal kimerik bir antikordur. Kimerik terimi ilacın insan ve murin komponentlerini içerdiğini ifade eder. Molekülün antijen bağlayıcı parçasının VK ve VH domainleri murin ve sabit Fc domaini insana aittir. Plazmadaki TNF- $\alpha$ ' ya bağlanırken aynı zamanda hücre yüzeyi üzerindeki TNF- $\alpha$ ' ya da bağlanır. AS' de $5 \mathrm{mg} / \mathrm{kg}$ dozda 0.2. 6. haftalarda ve sonrasinda her 6-8 haftada bir tekrarlanan infüzyonlar halinde uygulanır. Türkiye'de periferik artritte kontrendike olduğu durumlar kısaca aktif enfeksiyon, tedavi almamış tüberküloz, demiyelinizan hastalıklar, gebelik emzirme ve kardiyak yetmezlikler sayılabilir [23]. Anti TNF ajanların AS'de etkinliği 2014 yılında meta analizde hastalık aktivitesinde anlamlı düzelmelere sebep olduğu bildirilmiştir [32].

\section{Sertolizumab Pegol}

Sertolizumab (CZP), CDP870 diye bilinen insan monoklonal antikorunun Fab kısmının polietilen glikol ile kovalent olarak bağlanmasıyla elde edilen anti-TNF- $\alpha$ ajanıdır [33]. CZP'de GLM'ye benzer olarak hem solübl hemde transmembranöz TNF- $\alpha$ 'y1 nötralize eder. TNF- $\alpha$ reseptörlerindeki sinyal yolağını P55 ve P75 inibe eder. CZP'nin insan vücudunda monosit ve lenfosit apoptozunu indüklememesi kompleman bağlamaması, antikor bağımlı hücresel sitotoksiteye neden olmaması, nötrofil degranülasyonuna yol açmaması onu diğer TNF- $\alpha$ 'lardan farklı kılmaktadır [34-35].

RAPID-axSpA (aksiyel spondiloartropati) çalışmasında plasebo (PLS), CZP $200 \mathrm{mg}$ ve CZP 400 $\mathrm{mg}$ olan üç grupta inceleme yapılmıştır. CZP gruplarında 12. haftada ASAS20 cevab1 anlamlı bulunmuştur. BASFI BASDAI ve BASMI kriterlerinde 24. Haftada CZP gruplarında belirgin iyileşmeler saptanmıştır. Yan etkiler açısından PLS ile benzer olarak izlenmiştir.

Subkutan olarak 0, 2 ve 4 . haftalarda $400 \mathrm{mg}$ yükleme dozundan sonra $200 \mathrm{mg} 2$ haftada bir veya $400 \mathrm{mg} 4$ haftada bir devam dozu uygulanır [36-37].

\section{Ankilozan Spondilitte Anti-TNF- $\alpha$ Tedavi Kontrendikasyonları}

Gebelik ve süt emzirme, aktif enfeksiyon, ciddi enfeksiyon riski olan hastalar, tüberküloz öyküsü, 
doğal eklemde son bir yılda geçirilmiş septik artrit, kronik bacak ülseri, prostetik eklemde son 12 ayda geçirilmiş septik artrit, protez yerinde bırakılmışsa süre belirsizdir, pulmoner enfeksiyon, Kalıcı üriner kateter varlığ , multipl skleroz ve Lupus öyküsü, aşağıdaki durumlar hariç malign ve premalign durumlar: Bazal hücreli karsinom, on yıldan uzun bir süre önce tanı konulup tedavi edilmiş malign olgular [38].

\section{FARMAKOLOJIKK OLMAYAN TEDAVİLER}

\section{A. Egzersiz, Fizyoterapi ve Eğitim}

Farmakolojik olmayan tedavilerin en önemli kısmı hasta eğitimi ve düzenli egzersizlerdir. Ev egzersizleri etkindir. Su içinde veya su dışında bir terapistin gözetimi altında yapılan kişisel veya grup egzersizleri ev egzersizlerinden daha etkilidir [15]. Fizyoterapi de AS'li hastaların tedavisinin en önemli parçalarından biridir. AS'li hastaların tedavisinde fizyoterapi anti-inflamatuar tedaviye ek olarak kullanılmalıdır. Fizyoterapide amaç; hareket kısıtlılığ1 gelişmesini engellemek/geciktirmek, semptomları iyileştirmektir. Fizyoterapi hastaya tanı konduktan sonra başlanmalı ve multidisipliner devam etmelidir. As1l istenen fleksiyon deformitesini engellemek olduğundan omurga egzersizlerinde ekstansiyon / sırt ve bel güçlendirme hareketleri yapılmalıdır. Bununla birlikte akciğer kapasitesini artırmak için solunum egzersizleri yapılmalıdır. Bu egzersizler yaşam tarzına dönüştürülüp sürekli uygulanmalıdır [11].

\section{B. Yaşam Tarzı Değişiklikleri}

Yaşam tarzı modifikasyonlarını destekleyen az say1da delil vardır. Sigarayı bırakmanın faydalı olabileceğini destekleyen çalışmalar olmasına rağmen bu gözlemi destekleyen karşılaştırmalı çalışmalar bulunmamaktadır. Osteoporoz gelişim riski nedeniyle D vitamini ve kalsiyumdan zengin beslenilmelidir. Ayrıca bir vaka çalışması da karbonhidrattan fakir diyetin ağrıyı azaltmada etkili olduğunu göstermiştir [13].

\section{Cerrahi Tedavi}

Hastalarda kalça ekleminin tutulması ciddi özürlülüğe neden olabilir ve bu durumda total kalça protezi uygulanır. Vertebranın osteotomisi şiddetli spinal deformiteyi düzeltmek için uygulanmaktadır fakat risklidir. Ayrıca genel anestezi gerektiren herhangi bir cerrahi girişimde servikal vertebranın frajilitesi ve ağız açmadaki kısıtlılık nedeniyle entübasyon da dikkatli bir şekilde uygulanmalıdır [39].

\section{SONUÇ}

Ankilozan spondilit tedavisinde anti-TNF ilaçların kullanılması yeni bir akım oluşturmuştur. Tedavi düzenlenirken 2010 yılında yayınlanan ASAS/ EULAR tedavi önerileri dikkate alınmalıdır [40]. Konvansiyonel tedaviye rağmen sürekli aktif hastalığı olanlarda anti-TNF tedavi düşünülmelidir. $\mathrm{Bu}$ ilaçlar klinik belirti ve bulguları iyileştirmekle kalmayıp, hastanın fiziksel fonksiyonunu ve yaşam kalitesini iyileştirmekte, artmış olan akut faz yanıtını normale döndürmekte ve MR görüntülemede görülen inflamasyonu iyileştirebilmektedir. Anti-TNF- $\alpha$ ajanlarla tedavi edilen hastalar, başta tüberküloz olmak üzere, bakteriyel, viral, protozoal ve mantar enfeksiyonlarına eğilim oluşturmaktadır. Hastaların tedavi öncesi hem aktif hem de inaktif tüberküloz açısından değerlendirmeleri yapılmalı ve tedavi öncesi gerekliyse tüberküloz profilaksisi verilmelidir. Komplikasyonlarının önlenmesi için erken tedavi ve düzenli takip yapılmalıdır. Tedavi ve takip multidisipliner yaklaşım gerektirdiğinden hasta göz, kardiyoloji, gögüs hastalıkları, nefroloji, nöroloji, gastroenteroloji ve dermatoloji bölümleri ile gerektiğinde konsülte edilmelidir.

\section{KAYNAKLAR}

1. van der Linden S, van der Heijde D. Ankylosing spondylitis. Clinical features. Rheum Dis Clin North Am 1998;24:663676, vii.

2. Weisman MH RJ, Heijde D. Ankilozan Spondilit ve Spondiloartropatiler. Ankara: Veri Medikal Yayıncılık; 2008.

3. Dougados M, Dijkmans B, Khan M, et al. Conventional treatments for ankylosing spondylitis. Annals of the rheumatic diseases 2002, 61 Suppl 3:iii 40-50.

4. Lavie F, Pavy S, Dernis E, et al. Pharmacotherapy (excluding biotherapies) for ankylosing spondylitis: development of recommendations for clinical practice based on published evidence and expert opinion. Joint Bone Spine 2007;74:346-352.

5. Kwan D, William R. Bartle, and Scott E. Walker. The effects of acetaminophen on pharmacokinetics and pharmacodynamics of warfarin. J Clin Pharmacol 1999;9: 68-75.

6. Şahin E. Farmakolojik ajanlar. Fiziksel Tip ve Rehabilitasyon Pratik El Kitabı. Tan CJ, editör. Şendur ÖF, Çeviri ed. 2.baskı İstanbul: Güneş Tıp Kitabevleri;2008. p.333-357. 
7. Melli M, Kayaalp SO. Non-Steroidal antiinflamatuar ilaçlar. Kayaalp SO (Editör). Rasyonel Tedavi Yönünden Tibbi Farmakoloji 11. Bask1. Ankara: Hacettepe-Taş;2005 p.837-870.

8. Maugars Y, Mathis C, Berthelot JM, et al: Assessment of the efficacy of sacroiliac corticosteroid injections in spondylarthropathies: a double-blind study. Brit J Rheumatol 1996;35:767-770.

9. van den Berg R, Baraliakos X, Braun J, van der Heijde D. First update of the current evidence for the management of ankylosing spondylitis with non-pharmacological treatment and nonbiologic drugs: a systematic literature review for the ASAS/ EULAR management recommendations in ankylosing spondylitis. Rheumatology 2012;51:1388-1396.

10. Braun J, Pham T, Sieper J, et al: International ASAS consensus statement for the use of anti-tumour necrosis factor agents in patients with ankylosing spondylitis. Ann Rheum Dis 2003;62:817-824.

11. Ozgocmen S, Akgul O, Altay Z, et al: Expert opinion and key recommendations for the physical therapy and rehabilitation of patients with ankylosing spondylitis. Int J Rheum Dis 2012;15:229-238.

12. Brooks P. Slow acting anti rheumatic drugs and cytotoxic agents. In: Schumacher HR, ed. Primer on the Rheumatic Diseases. Atlanta: Arthritis Foundation; 1993. p303-6

13. Zochling J, van der Heijde D, Dougados M, Braun J: Current evidence for the management of ankylosing spondylitis: a systematic literature review for the ASAS/EULAR management recommendations in ankylosing spondylitis. Ann Rheum Dis 2006; 65:423-432.

14. Rudwaleit M, Listing J, Brandt J, et al. Prediction of a major clinical response (BASDAI 50) to tumour necrosis factor $\alpha$ blockers in ankylosing spondylitis. Ann Rheum Dis, 2004;63:665-670.

15. Braun J. V, Van Den Berg R, Baraliakos X, et al. 2010 update of the ASAS/EULAR recommendations for the management of ankylosing spondylitis. Ann Rheum dis 2011;70: 896-904.

16. van der Heijde D, Sieper J, Maksymowych WP, et al. 2010 Update of the international ASAS recommendations for the use of anti-TNF agents in patients with axial spondyloarthritis. Annals of the rheumatic diseases 2011;70:905-908.

17. van der Heijde D, Dijkmans B, Geusens P, et al. Ankylosing Spondylitis Study for the Evaluation of Recombinant Infliximab Therapy Study G: Efficacy and safety of infliximab in patients with ankylosing spondylitis: results of a randomized, placebo-controlled trial (ASSERT). Arthrit Rheum 2005;52:582-591.

18. Braun J, Brandt J, Listing J, et al. Treatment of active ankylosing spondylitis with infliximab: a randomised controlled multicentre trial. The Lancet 2002;359:1187-1193.

19. Davis JC Jr, Van Der Heijde D, Braun J, et al. Recombinant human tumor necrosis factor receptor (etanercept) for treating ankylosing spondylitis: a randomized, controlled trial. Arthrit Rheum 2003; 48:3230-3236.

20. Inman RD, Davis JC Jr, Heijde D, et al. Efficacy and safety of golimumab in patients with ankylosing spondylitis: results of a randomized, double-blind, placebo-controlled, phase III trial. Arthrit Rheum 2008; 58:3402-3412.

21. Braun J, Davis J, Dougados M, et al. First update of the international ASAS consensus statement for the use of anti-TNF agents in patients with ankylosing spondylitis. Ann Rheum Dis 2006; 65:316-320.
23. Saag KG, Teng GG, Patkar NM, et al. American College of Rheumatology 2008 recommendations for the use of nonbiologic and biologic disease-modifying antirheumatic drugs in rheumatoid arthritis. Arthrit Care Res 2008;59:762-784.

24. Black R A, Rauch CT, Kozlosky CJ, et al. A metalloproteinase disintegrin that releases tumour necrosis factor-R from cells. Nature 1997;385:729-733.

25. Pay S. Romatizmal Hastalıklarda Anti-TNF İlaç Kullanımı. Turkiye Klinikleri J Med Sci, 2006;26:430-440.

26. Gorman JD, Sack, K E, Davis JC Jr. Treatment of ankylosing spondylitis by inhibition of tumor necrosis factor $\alpha$. N Engl J Med 2002;346:1349-1356.

27. Dvis JC, Webb A, Lund S, Sack K, Result from an open-label extension study of etanercept in ankylosing spondylitis. Art Rheum 2004;51:302-104

28. Brandt J, Listing J, Haibel H, et al. Long-term efficacy and safety of etanercept after readministration in patients with active ankylosing spondylitis. Rheum 2005;44:342-348.

29. Den Broeder AA, Saxne T, Heinegård D, et al. Long term antitumour necrosis factor $\alpha$ monotherapy in rheumatoid arthritis: effect on radiological course and prognostic value of markers of cartilage turnover and endothelial activation. Ann Rheum Dis 2002; 61:311-318.

30. U.S Food and Drug administration, Full prescribing information, Adaliumab.2008. Available at:www.fda.gov.

31. Tracey D, Klareskog L, Sasso EH, et al. Tumor necrosis factor antagonist mechanisms of action: a comprehensive review. Pharmacol Ther 2008;117:244-279.

32. Callhoff J, Sieper J, Weiß A, et al. Efficacy of TNF $\alpha$ blockers in patients with ankylosing spondylitis and non-radiographic axial spondyloarthritis: a meta-analysis. Ann Rheum Dis doi:10.1136/ 2014-205322 [Epub ahead of print]

33. Patel Aarat M, and Larry W. Moreland. "Certolizumab pegol: a new biologic targeting rheumatoid arthritis. Ann Rheum Dis 2010;6: 855-866.

34. Nesbitt A, Fossati G, Bergin M, et al. Mechanism of action of certolizumab pegol (CDP870): In vitro comparison with other anti-tumor necrosis factor $\alpha$ agents. Inflamm Bowel Dis 2007;13:1323-1332.

35. Evans Ashley T, Lee SD. "A review and expert opinion of the use of certolizumab for Crohn's disease. Expert Opin Biol Ther 2012; 12:363-370.

36. Landewé R, Braun, J, Deodhar A, et al . Efficacy of certolizumab pegol on signs and symptoms of axial spondyloarthritis including ankylosing spondylitis: 24-week results of a double-blind randomised placebo-controlled Phase 3 study. Ann Rheum Dis 2013;73:39-47.

37. Dhillon S: Certolizumab pegol: a review of its use in patients with axial spondyloarthritis or psoriatic arthritis. Drugs 2014;74:999-1016.

38. Braun J, Davis J, Dougados M, et al. First update of the international ASAS consensus statement for the use of anti-TNF agents in patients with ankylosing spondylitis. Ann Rheum Dis 2006; 65:316-320.

39. Davis JC. Ankylosing Spondylitis In: Koopman WJ, Moreland LW (eds). Arthritis and Allied Conditions. A Textbook of Rheumatology Lippincott Williams and Wilkins P. 2005 p.1319-1333.

40. Braun Jv, Van Den Berg R, Baraliakos X, et al. : 2010 update of the ASAS/EULAR recommendations for the management of ankylosing spondylitis. Ann Rheum Dis 2011;70:896-904. 